Case IV. has remained in excellent condition (see fig. 3). $\mathrm{He}$ is in training for racing.

Case V. There has been no recurrence of the disease in police horse No. 12, Bilbeis, now at work in Cairo City Police. Was reinspected and photographed on 29th April. His condition was excellent, as may be seen from fig. 4.

Case VI., English horse, Rego, I am informed, had a relapse in the first week of April.

\title{
SOME OBSERVATIONS ON TUBERCULOSIS IN CAMELS IN EGYPT.
}

By F. Eugene Mason, M.R.C.V.S., Director of Vaccine Institute, Public Health Department, Cairo.

IN the Journal of Comparative Pathology and Therapeutics, I9Io, two articles have appeared, one by Archibald and the second by Leese, under the heading "Acid-fast Bacilli in the Lungs of a Camel associated with Lesions resembling those of Miliary Tuberculosis." From these articles it appears that tuberculosis is a very rare disease amóngst camels outside Egypt. In fact the only cases recorded (except those occurring in zoological gardens, in which camels lead an unnatural life) appear to be :-

One case reported by Lingard in Annual Report of Imperial Bacteriologist, India, 1905-06.

One case reported by Leese in India in Annual Report of Officer Investigating Camel Diseases, I908.

One case recorded by Captain Archibald, R.A.M.C.. in the AngloEgyptian Sudan, published in The Journal of Comparative Pathology and Therapeutics, 1910.

I also remember reading an account of a case reported in Algeria, but cannot trace the literature.

In Egypt the disease has long been recognised to be a common one among camels, and was first reported by Littlewood, Journal Official Egyptien, I888; J. B. Piot Bey has also observed the condition macroscopically, but has not placed his observations on record. The causal organism was not demonstrated or inoculation experiments made to prove the nature of the disease until 25th January I9II. On this date lungs from a camel killed at Cairo Abattoir showing miliary lesions were examined; the bronchial glands were much enlarged and caseous.

Acid-fast bacilli morphologically resembling tubercle bacilli were numerous in the exudate in the bronchial tubes, and were also seen in stained sections of the tubercles. The latter were typically tuberculous in structure, but giant cells were rare.

Two guinea-pigs were inoculated subcutaneously with pulp made from young tubercles in normal saline solution. One died on the fifty-first day, and the second was chloroformed when moribund on the sixty-seventh day. Autopsies on both guinea-pigs showed generalised tuberculosis and a large dryish ulcer at the point of inoculation. Acid-fast bacilli morphologically similar to tubercle bacilli were recovered in large numbers from the lesions found in 
lungs, liver, lymphatic glands, and also from the local ulcerations which occurred at the points of inoculation.

Two rabbits were inoculated subcutaneously, one with emulsion in normal saline of young tubercles from camel lung, and the other with a small quantity of exudate extracted from a bronchus in which acidfast bacilli with the characters of tubercle bacilli had been detected.

The first rabbit died on the sixty-fifth day; a very extensive tuberculosis of the lungs was found, these organs being literally crammed with innumerable tubercles very rich in tubercle bacilli. The bronchial and mediastinal glands were much enlarged and caseous. There was also a large dryish ulcer at the point of inoculation; other organs normal.

The second rabbit was chloroformed when nearly dead on the seventy-fifth day.

The autopsy showed generalised tuberculosis with very numerous and extensive lesions in the lungs, liver, and all the lymph glands of the body. The spleen was enlarged but without tubercle formation. There was a dry ulcer at the inoculation point. Tubercle bacilli were very numerous in smears and sections made from the diseased organs, and were also recovered from the local ulcer.

Cultures were started on solid camel-blood serum from an inguinal gland of the second rabbit.

These, which proved to be pure cultures of acid-fast bacilli resembling tubercle bacilli morphologically, grew very slowly, with all the characters of tubercle bacilli of the bovine type. Sub-cultures on glycerine bouillon showed differences of character from the three recognised types of tubercle bacilli when grown on that medium. The matter is still under study.

From 27th March I9I I for the period of one year a systematic examination was made of all cases of suspected tuberculosis seen in camels slaughtered in Cairo Abattoir.

Cases were only recorded as tuberculous when the lesions were in accordance with this disease, and were found on microscopic examination to contain acid-fast bacilli morphologically resembling tubercle bacilli.

Twenty cases were recorded during the year and they all occurred in Egyptian bred camels. During the summer months many camels reach the Cairo Abattoir coming from the Sanai Peninsula and from Arabia. No case of tuberculosis was seen amongst these.

Lesions of Tuberculosis in the Camel.-The lungs and bronchial glands are by far the most common seats of disease, and the pleura is frequently studded with "grapes," particularly the fringe along the lower borders of the posterior lobes.

The gross lesions found are discrete tubercles scattered throughout the lung substance, or masses of confluent tubercles, caseous masses and fibrous tissue. In some cases a large portion of a lobe may be completely solid, being filled with caseous matter and fibrous tissue.

The mediastinal as well as the bronchial glands are frequently enormously enlarged and caseous. The lesions on the pleura resemble the well-known "grapes" seen in cattle.

In seventeen out of twenty cases the lesions were confined to the thorax. 
Adhesions were several times noted, also "grapes" upon the pericardium.

It was also noticed that with a very extensive tuberculosis of the lungs, bronchial glands, and visceral pleura, the parietal pleura and supra-sternal glands were not infrequently unaffected.

One case of generalised tuberculosis was recorded with very numerous lesions in lungs, liver, spleen, and kidneys. There were also tuberculous pleurisy, pericarditis, and caseous lesions projecting into the branches of the pulmonary artery.

In one case the lungs and liver were affected.

In one case there were extensive tuberculous lesions in lungs, pleura, pericardium, and liver. The latter organ was also the seat of a well-marked fine cirrhosis.

Histologically the lesions of tuberculosis of the camel were found to consist of the usual elements, except that giant cells were very rare.

\title{
SOME ENTOZOA OF INDIAN ELEPHANTS; AND A GASTRODISC (?) FROM AN INDIAN ZEBU.
}

\author{
By S. N. MitTeR, G.B.V.C., Calcutta. \\ (From the Raymond Research Laboratory.)
}

LAST year some specimens of entozoa were presented to this Laboratory by Mr D. Quinlan, M.R.C.V.S., of the Civil Veterinary Department, Bengal, to whom many thanks are due for his kind and constant help. Amongst them were the following interesting nematodes from the intestines of Indian elephants (elephas Indicus) that died in Angul. They were collected by the local Veterinary Assistant, Mr J. L. Bose, G.B.V.C., who was in charge of a number of Government elephants. The parasites were preserved in solution of formalin, and, owing to the length during which they had remained in that fluid, they were so shrivelled up as to preclude examination of many histological details. After considerable immersion in clearing medium the parasites appeared more or less transparent and disclosed their main features, which are recorded below :-

I. Sclerostoma Sipunculiforme (Baird).-This parasite was first described in 1859 by $\mathrm{Dr}$ Baird in the Proceedings of the Zoological Society. In I88I it was again studied and commented upon by Dr Cobbold in the Transactions of the Linnean Society. In India only a $q$ specimen has been roughly recorded by Lieutenant-Colonel Evans and Mr Rennie from Burmah. The body is thick, smooth, and striated transversely. The head is quite distinct, and is attached to a constricted neck. The mouth is circular, and furnished with a large number of fine straight teeth in two rows. The buccal capsule is deep and cup-shaped, and followed by a small thick muscular cesophagus. The caudal bursa longer than broad, carrying twenty rays. The spicules were almost of equal length, and situated parallel. The tail of the female is divided by a hollow groove into two portions, one being round and the other conical and pointed. The uterus is double. The anal and genital pore are situated together in the deep hollow at the base of the tail. The length of the male is nearly $25 \mathrm{~mm}$., that of the female $28 \mathrm{~mm}$. 